\title{
Early Neuronal and Glial Fate Restriction of Embryonic Neural Stem Cells
}

\author{
Delphine Delaunay, ${ }^{1,2}$ Katharina Heydon, ${ }^{1,2}$ Ana Cumano, ${ }^{3}$ Markus H. Schwab, ${ }^{4}$ Jean-Léon Thomas, ${ }^{1,2}$ Ueli Suter, ${ }^{5}$ \\ Klaus-Armin Nave, ${ }^{4}$ Bernard Zalc, ${ }^{1,2}$ and Nathalie Spassky ${ }^{1,2}$ \\ Inserm, Unité 711, 75013 Paris, France, ${ }^{2}$ Institut Fédératif de Recherche 70, Faculté de Médecine, Université Pierre et Marie Curie, 75013 Paris, France, \\ ${ }^{3}$ Inserm, Unité 668, Institut Pasteur, 75724 Paris Cedex 15, France, ${ }^{4}$ Max-Planck-Institute of Experimental Medicine, D-37075 Goettingen, Germany, and \\ ${ }^{5}$ Institute of Cell Biology, Swiss Federal Institute of Technology (ETH), ETH Hönggerberg, CH-8093 Zürich, Switzerland
}

The question of how neurons and glial cells are generated during the development of the CNS has over time led to two alternative models: either neuroepithelial cells are capable of giving rise to neurons first and to glial cells at a later stage (switching model), or they are intrinsically committed to generate one or the other (segregating model). Using the developing diencephalon as a model and by selecting a subpopulation of ventricular cells, we analyzed both in vitro, using clonal analysis, and in vivo, using inducible Cre/loxP fate mapping, the fate of neuroepithelial and radial glial cells generated at different time points during embryonic development. We found that, during neurogenic periods [embryonic day 9.5 (E9.5) to 12.5], proteolipid protein ( $p l p)$-expressing cells were lineage-restricted neuronal precursors, but later in embryogenesis, during gliogenic periods (E13.5 to early postnatal), plp-expressing cells were lineage-restricted glial precursors. In addition, we show that glial cells forming at E13.5 arise from a new pool of neuroepithelial progenitors distinct from neuronal progenitors cells, which lends support to the segregating model.

Key words: diencephalon; plp; mouse; in vivo genetic fate mapping; neuroblast; glioblast

\section{Introduction}

The question of how neurons and macroglial cells are generated during development in ventricular proliferative zones of the neural tube has a long history. Wilhelm His suggested the existence of two cell lines in the ventricular zone ("segregating model"), one giving rise to neurons ("neuroblasts") and the other to glia ("spongioblasts") (His, 1889). His' model was soon contested by Schaper (1897) and later by Sauer (1935) who proposed that a single homogeneous proliferative cell population gives rise to both neurons and glia. Pulse-chase experiments led Fujita (Fujita and Fujita, 1963; Fujita and Nakai, 1966) to support and complement the hypothesis of a single progenitor population that generates neurons and glial cells sequentially ("switching" model). Over the years, reports have alternated in support of one model

\footnotetext{
Received Feb. 4, 2007; accepted Jan. 14, 2008

This work was supported by Inserm, by grants from Association de Recherche sur la Sclérose En Plaques (J.-L.T.), National Multiple Sclerosis Society Grant TR-3762-A-1 (B.Z.), the Swiss National Science Foundation and the National Center of Competence in Research "Neural Plasticity and Repair" (U.S.), and Deutsche Forschungsgemeinschaft and Bundesministerium für Bildung und Forschung (K.-A.N.). We thank Drs. A. Ghysen and W. R. Richardson for careful reading and helpful comments on this manuscript, F. Zimmerman for pronucleus injections, R. Sprengel for cre CDNA, H. Takebayashi for Cre plasmid used for ISH, and C. Lagenaur, N. Heintz, and P. Leprince for the gift of precious antibodies. The M2 and the M6 hybridomae developed in the laboratory were obtained from the Developmental Studies Hybridoma Bank developed under the auspices of the National Institute of Child Health and Human Development and maintained by the University of lowa, Department of Biological Sciences (lowa City, IA). The plp-gfp transgenic mouse has been generated by Dr. C. Goujet (Service d'Experimentation Animale et de Transgenese, Villejuif, France). D.D. was a fellow of the Ministère de l'Enseignement Supérieur et de la Recherche and European Leukodystrophy Association.

Correspondence should be addressed to B. Zalc, Biologie des Interactions Neurones/Glie, Inserm Unité 711, Université Pierre et Marie Curie, Hôpital de la Salpêtrière 75651 Paris cedex 13, France.E-mail:berzalc@ccr.jussieu.fr. DOI:10.1523/JNEUROSCI.5497-07.2008

Copyright $\odot 2008$ Society for Neuroscience $\quad 0270-6474 / 08 / 282551-12 \$ 15.00 / 0$
}

or the other (Briscoe et al., 2000; Anderson, 2001; Stiles, 2003; Noble et al., 2004). The segregating model has been supported by Rakic and coworkers, who provided evidence, at the ultrastructural level, of the coexistence of neuronal and glial precursor cells in the cerebral ventricular zone of the fetal monkey (Levitt et al., 1981). Clonal analyses have since shown that neuronal-restricted and glial-restricted progenitors, responsible for the production of only neurons or only glia, can be isolated from the embryonic spinal cord and cerebral cortex (Davis and Temple, 1994; MayerProschel et al., 1997; Rao et al., 1998; Qian et al., 2000). Retroviral labeling and genetic fate-mapping experiments have also suggested a very early and regional segregation of neuronal and glial progenitor cells (Luskin et al., 1993; Mione et al., 1997; McCarthy et al., 2001; Lyons et al., 2003; Wu et al., 2006; Battiste et al., 2007). In contrast, the switching model is consistent with what is known about the origins of neurons and glia in invertebrates. In grasshopper and Drosophila, asymmetric division of neuroblasts produces another neuroblast and a precursor cell, which on division produces either two neurons, two glial cells, or one of each (Udolph et al., 1993; Doe et al., 1998). In vertebrates, the existence in the cerebral cortex of cells capable of generating both neurons and oligodendrocytes has been postulated based on retroviral labeling experiments and clonal analysis (Williams et al., 1991; He et al., 2001; Yung et al., 2002). Furthermore, neurons and glia emerge simultaneously in common territories and a number of intrinsic and extrinsic regulatory mechanisms are essential for both neurogenesis and gliogenesis, suggesting that they could be derived from a common progenitor (Bertrand et al., 2002; Rowitch, 2004; Deneen et al., 2006; Petryniak et al., 2007). Along the same line are the data reported by the group of Yi Sun, 
showing that DNA methylation in neural progenitors leads to switching from neurogenesis to gliogenesis (Fan et al., 2005).

In the early embryo, the primitive neural tube is composed of neuroepithelial cells, which contact both the ventricular and the pial surface. Radial glia designate cells that have their soma in the ventricular zone, in which they contact the lumen of the ventricles and possess a long process that extends toward the pial surface (Rakic, 1971a,b). Both, neuroepithelial cells and radial glia express the intermediate filament nestin (Lendahl et al., 1990). Radial glia, however, can be distinguished from neuroepithelial cells by the expression of an array of markers such as the murine radial glia-specific marker RC2 (Misson et al., 1988), the astrocyte-specific glutamate transporter (GLAST) (Shibata et al., 1997), and the brain-lipid-binding protein (BLBP) (Feng et al., 1994). It has long been accepted that radial glia are astroglial progenitors (Schmechel and Rakic, 1979; Levitt et al., 1981; Voigt, 1989). It has also been proposed that radial glia serve as oligodendrocyte progenitors (Choi and Kim, 1985, Hirano and Goldman, 1988). Finally, recent evidence from several laboratories has demonstrated that radial glia produce most of the cortical neurons (Malatesta et al., 2000; Hartfuss et al., 2001; Miyata et al., 2001; Noctor et al., 2001; Tamamaki et al., 2001; Wu et al., 2005). The fact that neurons and glia are the progeny of a common progenitor pool that share intrinsic and extrinsic regulatory mechanisms is therefore generally agreed. However, whether neurons and glia are derived from separate progenitor cells (segregating model) or whether they are generated from a progenitor common to both lineages (switching model), using asymmetric division, has remained unclear so far.

To gain additional insight into the lineage relationship between neurons and glia in the ventral diencephalon in vivo, we created a transgenic mouse line in which the CRE recombinase gene is controlled by proteolipid protein ( $p l p)$ regulatory elements. Although PLP is the major protein of myelin, its transcript has been reported to be expressed by a subpopulation of progenitor cells in the basal plate of the diencephalon (bpd) from embryonic day 9.5 (E9.5) onward (Timsit et al., 1995; Puelles and Rubenstein, 2003), i.e., long before myelin is deposited. Using Cre/loxP in vivo fate mapping, we found that $p l p$-expressing cells generate subgroups of thalamic neurons as well as astrocytes, oligodendrocytes, and ependymal cells. Dissociated clonal cultures from $p l p$-expressing cells isolated by fluorescence-activated cell sorting (FACS) from the diencephalon of plp-green fluorescent protein (GFP) (Spassky et al., 2001b) mice show a restricted neuronal or glial fate when isolated at E9.5 or E13.5, respectively. Finally, we show that radial glial cells that express plp in the diencephalon at E13.5 are not the progeny of neuroepithelial cells expressing $p l p$ at E9.5. Together, our data suggest that, in the basal plate of diencephalon, a subpopulation of neuroblasts and glioblasts characterized by the expression of $p l p$ is segregated early during development.

\section{Materials and Methods}

Animals. To achieve Cre recombinase expression under control of regulatory elements of the PLP gene, we generated a construct that contained $3.74 \mathrm{~kb}$ of $5^{\prime}$ flanking sequence, exon 1 , and the 8.15 -kb-long intron 1 of the murine PLP gene, and a cDNA encoding Cre recombinase [from pMC-Cre (Gu et al., 1994)], fused into PLP exon 2. First, a $1.12 \mathrm{~kb} \mathrm{3'}$ fragment of intron 1 was fused to a $380 \mathrm{bp} 5^{\prime}$ fragment of Cre (including a nuclear localization sequence) by PCR, using the following primers: PLPI sense, 5'-CCA TCG ATG AAT TCC AAG TAT ATT TAC CCT C-3'; PLPI antisense, 5' -CTG GGG AAG AAG AAG GAG-3'; PLPCre sense, 5' -CTC CTT CTT CTT CCC CAG GCC CCA AGA AGA AGA GG-3'; and PLPCre antisense, 5' -TTC GGA TCC GCC GCA TAA C-3'.
The fusion product was cloned (EcoRI/BamHI) into pBluescript KS+ (Stratagene, La Jolla, CA), and the $1.26 \mathrm{~kb} 3^{\prime}$ fragment of Cre (harboring a simian virus 40 polyadenylation signal) was added by Bam HI cloning. Next, by ClaI/EcoRI partial digestion, a fragment containing $3.74 \mathrm{~kb}$ of the PLP $5^{\prime}$ flanking sequence, exon 1 , and $1.96 \mathrm{~kb}$ of intron 1 was inserted. The construct was completed by subcloning of a $5.07 \mathrm{~kb}$ EcoRI fragment of intron 1 that was generated by EcoRI partial digestion. The entire construct was linearized with NotI, and the vector backbone was removed by partial digestion with KpnI. Pronuclear injection of transgene DNA $(1-2 \mathrm{ng} / \mu \mathrm{l})$ into mouse oocytes $(\mathrm{DBA} 2 \times \mathrm{C} 57 \mathrm{BL} / 6 / \mathrm{N})$ was performed by standard procedures (Hogan et al.,1994). Routine genotyping was performed by PCR on tail genomic DNA using primers PLPI sense and PLPCre antisense. All the other transgenic mice were generated using the same $p l p$ expression cassette. The $p l p-s h b l e-l a c Z$ and the $p l p-$ $g f p$ mice were generated in DBA2 $\times \mathrm{C} 57 \mathrm{BL} / 6 / \mathrm{N} \mathrm{F} 1$ and maintained homozygous in the C57BL/6/N strain (Spassky et al., 1998, 2001b). The plp-CreERT2 mouse (Leone et al., 2003) was generated using an improved tamoxifen (TM) inducible variant of the CRE recombinase (CreERT2) (Metzger and Chambon, 2001). This line was generated using $\mathrm{DBA} 2 \times \mathrm{C} 57 \mathrm{BL} / 6 / \mathrm{N} \mathrm{F} 1$ females. Rat embryos were obtained from pregnant Wistar rats (Elevage, Janvier, France). For mouse and rat, the midpoint of the dark interval during which mating occurred was designated as day 0 , and the embryos were considered to be E0.5 on the morning after fertilization. The rats were considered at the same developmental stage as the mice $1.5 \mathrm{~d}$ later.

Mouse breeding. The plp-shble-lacZ and plp-gfp mice were crossed with OF1 females (Iffa Credo, L'Arbresle, France), and animals used were therefore heterozygous. The plp-Cre and the plp-CreERT2 mice were crossed either with $R 26 R$ (Soriano, 1999) or the Z/EG reporter mice (Novak et al., 2000). The difference observed between offspring generated from this two reporter transgenic mice was quantitative: more cells were generated from $R 26 R$ than from $Z / E G$ mice.

Tamoxifen treatment. TM (T5648; Sigma, St. Louis, MO) was dissolved in a DMSO/ethanol/sunflower oil (4:6:90) mixture at the concentration of $10 \mathrm{mg} / \mathrm{ml}$. Pregnant mother mice were injected intraperitoneally with $1 \mathrm{mg}$ of tamoxifen per $10 \mathrm{~g}$ of body weight. Embryos were then analyzed at birth.

Cell culture. The basal plate of the diencephalon of rat and mouse embryos was dissected from E9.5 to E14.5 in Ca2 ${ }^{+} / \mathrm{Mg} 2^{+}$free HBSS (Invitrogen, Carlsbad, CA). Cells were dissociated by digestion with trypsin (Biological Industries, Beth Haemek, Israel) diluted at $2.5 \mathrm{ng} / \mathrm{ml}$ in 2 $\mathrm{ml}$ of HBSS. After $10 \mathrm{~min}$ at $37^{\circ} \mathrm{C}, 2 \%$ FCS (Invitrogen) was added, and the solution was completed to $8 \mathrm{ml}$ with HBSS and centrifuged for $5 \mathrm{~min}$ at $1000 \mathrm{rpm}$. Before FACS, mouse cells were resuspended in $2 \mathrm{ml}$ of PBS containing $2 \%$ FCS and filtered through a $70 \mu \mathrm{m}$ nylon mesh (VWR, Fontenay-sous-Bois Cedex, France). Then, propidium iodide (Sigma) was added to eliminate dead cells during sorting.

For the mouse coculture system, rat feeder cells were put at $1.10^{5}$ cells per poly-L-lysine (PLL) (Sigma) 14-mm-diameter coated glass coverslips in a $30 \mu \mathrm{l}$ of DMEM (Invitrogen) $/ 10 \%$ FCS (Invitrogen) drop, less than $2 \mathrm{~h}$ before plating the cells sorted from mouse bpd. Fifty sorted mouse cells were put on each coverslip. Thirty minutes after sorting, $450 \mu \mathrm{l}$ of Bottenstein and Sato (BS) medium (Bottenstein and Sato, 1979) supplemented with $1 \%$ FCS and $1 \%$ penicillin-streptomycin was added in each of the 24 wells. The cells were maintained in culture during 5, 10, or $15 \mathrm{~d}$. The medium was never replaced to maintain an optimal concentration of factors synthesized by the rat feeder. This clonal coculture system provides a diencephalic environment for the sorted cells similar to that encountered during normal development, without the addition of specific growth factors that may bias the analysis by selecting for particular cell types (Williams et al., 1991; Lillien, 1997; Qian et al., 1998). To validate this system for clonal analysis, we first ensured that all cells derived from mouse diencephalon were labeled by the M2/M6 monoclonal antibodies (mAbs) (data not shown). Cells were allowed to grow for $10 \mathrm{~d}$, and only clusters containing at least two cells were considered for analysis.

For neurosphere cultures, after bpd dissection as described above, $\mathrm{GFP}^{+}\left(p l p^{+}\right)$cells were sorted by FACS as described above, and 50 or 10 $\mathrm{GFP}^{+}$cells (at E9.5 and E13.5, respectively) were plated into a 96-well plate. Mouse cells were grown in DMEM/F-12 medium (Invitrogen) 
containing N2 and B27 supplements (1:100, 1:50; Invitrogen) plus basic FGF (20 ng/ml; Roche Diagnostics, Basel, Switzerland) and epidermal growth factor (EGF) $(10 \mathrm{ng} / \mathrm{ml}$; Roche) for $10-15 \mathrm{~d}$, to allow generation of same size neurospheres. To test self-renewal, neurospheres were dissociated by digestion with trypsin (Biological Industries), and the resulting cells were clonally distributed and then allowed to proliferate in EGFand FGF-2-containing medium. To allow differentiation, the neurospheres were dissociated or left intact and plated on culture plates coated with PLL, in BS 1\% FCS for a period of $5 \mathrm{~d}$. For cell-type analysis, cells were fixed in $4 \%$ paraformaldehyde and stained with $\mathrm{TuJ} 1, \mathrm{O} 4$, and anti-glial fibrillary acidic protein (GFAP) antibodies (Abs).

FACS and clonal analysis. Cells were sorted from the brain of $p l p-g f p$ mice at two ages: E9.5 and E13.5. Cell sorting was performed with a MoFLo (DakoCytomation, Carpinteria, CA) in the single-cell mode at the appropriate sorting rate. At each stage and for each experiment, purity of the sorted cells was reassessed by flow cytometry of an aliquot and on average comprised between 95 and 99\% (see Fig. 3B-D). In a second set of experiments, we verified the purity of our cells by immunocytochemistry $2 \mathrm{~h}$ after the sorting experiment, with the same results.

The clonal probability follows the Poisson distribution, indicating that we are clonal at E9.5, considering the number of negative coverslips. At E13.5, we were not properly clonal, so we calculated the probability of clonal superimposition as performed in retroviral experiments (Williams et al., 1991; Malatesta et al., 2000), and we found $7.4 \times 10^{-4} \%$. Data were derived from at least two different batches. After $10 \mathrm{~d}$ in vitro (DIV), the mean number of clones (calculated from the values obtained per 12-mm-diameter coverslip containing M2/M6-positive clones) were $2.4 \pm 0.5$ and $3.1 \pm 0.5$, respectively, for cultures derived from E9.5 or E13.5, whereas the mean number of cells in each clone was $19.4 \pm 2.7$ and $7.7 \pm 0.9$ for cultures derived from E9.5 or E13.5, respectively. The number of clones analyzed was 65 at E9.5 and 159 at E13.5.

Antibodies, immunolabeling, and detection of $\beta$-galactosidase enzymatic activity. The following mouse mAbs were used: A2B5 [1:5 (Eisenbarth et al., 1979)], O4 [1:5 (Sommer and Schachner, 1981)], M2/M6 mAb [1:5 and 1:10 (gift from C. Lagenaur, Developmental Studies Hybridoma Bank)], anti-nestin (1:300; Invitrogen), anti-adenomatous polyposis coli (CC1, 1:40; Oncogene Sciences, Uniondale, NY), neuronal-specific nuclear protein (NeuN) (1:1000; Invitrogen), TuJ1 (1:500; Covance Research Products, Berkeley, CA), RC2 (1:50; gift from P. Leprince, Université de Liège, Liège, Belgium), anti-CRE-2D8-As or C7920 (1:250 or 1:500; Euromedex, Mundolsheim, France), and rat mAb anti-GFP (1: 1000; Nacalai, Osaka, Japan). Polyclonal antibodies raised in the rabbit were anti-BLBP (1:1000; gift from N. Heintz, The Rockefeller University, New York, NY), anti-GFAP (1:400; DakoCytomation), and anti-GFP (1:1000; Invitrogen); in guinea pig, they were anti-GLAST (1:1000; Chemicon, Temecula, CA); in the goat, they were anti- $\beta$-galactosidase ( $\beta$-gal) (1:1000; Chemicon); and appropriate secondary antibodies were fluorescence-conjugated (Alexa, 1:1000; Invitrogen) or biotinylated for $\mathrm{DAB}$ and streptavidin coumarine detection. We further used the $\mathrm{ABC}$ Vectastain kit for DAB detection as well as the Substrate Kit Vector SG (Vector Laboratories, West Grove, CA). Immunolabeling of cultures or tissue sections and detection of $\beta$-galactosidase enzymatic activity were as described previously (Spassky et al., 1998). Figures 1, 2, and 5 were obtained using a confocal laser microscope (Leica, Nussloch, Germany), and the software used was Leica lite, NIH ImageJ, and Photoshop (Adobe Systems, San Jose, CA).

\section{Results \\ plp transgenes are expressed by both neuroepithelial and radial glial cells}

Previous studies have shown that $p l p$ transcripts are expressed in the ventricular layer of the laterobasal plate of the diencephalon already at E9.5 (Ikenaka et al., 1992; Timsit et al., 1992, 1995). To identify $p l p$-expressing cells, we took advantage of the $p l p$ transgenic mice, in which expression of the $\beta$-galactosidase or GFP reporter genes are driven by plp regulatory sequences (Spassky et al., 1998, 2001b; Thomas et al., 2000) (Fig. 1A,B). Coronal sections of E9.5 and E13.5 transgenic embryos were double immu- nostained with anti- $\beta$-galactosidase (or anti-GFP; data not shown) and a battery of antibodies, specific for either neuroepithelial or radial glial cells. At E9.5, plp-expressing cells ( $\beta$ galactosidase ${ }^{+}$or $\mathrm{GFP}^{+}$) were nestin ${ }^{+}$neuroepithelial cells (Fig. 1C). At this developmental stage, RC2, BLBP, and GLAST were not detectable (data not shown). At E13.5, plp $^{+}$cells in the ventricular layer were radial glial cells coexpressing nestin, BLBP, RC2, and GLAST (Fig. 1D). At E9.5 and E13.5 plp-expressing cells in the laterobasal plate of the diencephalon have therefore distinct neuroepithelial and radial glial cell phenotypes, respectively.

\section{$p l p$-expressing cells generate all major types of neural cells}

To label the entire progeny of $p l p$-expressing cells, we exploited a recombinase-based fate-mapping technique that transforms transient gene expression into a permanent inheritable lineage marker (Dymecki and Tomasiewicz, 1998; Zinyk et al., 1998). This approach is based on the cell-type-specific expression of CRE recombinase that mediates the deletion of a stop cassette flanked by loxP sites. Four independent plp-CRE transgenic founder lines were generated. Plp-CRE mice were crossed to the Rosa26-lox-lacZ (R26R) or $\beta$-actin-lox-GFP (Z/EG) reporter strains, which have been shown to drive high levels of reporter expression in all embryonic tissues (Soriano, 1999; Novak et al., 2000). To ensure that our fate mapping reflects recombination in plp-expressing cells and not ectopic CRE expression, the recombination pattern in the plp-CRE;R26R double-transgenic mouse was compared with the pattern of $\beta$-galactosidase in the previously characterized plp-shble-lacZ mouse. At E10.5, wholemount preparations or coronal sections of double-transgenic plp-CRE;R26R embryos stained for $\beta$-gal activity revealed a staining pattern similar to that observed in the plp-shble-lac $Z$ mouse (compare Figs. $1 A, B$ and $2 A, B$ ). We also verified on coronal sections across the diencephalon of E10.5 plp-CRE embryos that the localization of cells expressing CRE recombinase had a pattern superimposable on that of $\beta$-gal ${ }^{+}$cells in the plp-shblelac $Z$ line (data not shown). At E13.5, $\beta$-gal ${ }^{+}$cells in the ventricular zone expressed GLAST, suggesting that they were indeed radial glial cells (Fig. 2C).

To identify which populations are derived from plpexpressing cells, we next examined recombination in postnatal mice. Coronal sections across the diencephalon of P15 plp-CRE; $Z / E G$ mice were immunolabeled with a combination of anti-GFP and cell-type-specific markers. GFP was consistently detected in cells with typical morphology of mature oligodendrocytes and labeled with $\mathrm{CC} 1 \mathrm{mAb}$, an oligodendroglial-specific marker (Bhat et al., 1996) (Fig. 2D). Other $\mathrm{GFP}^{+}$cells, localized in the parenchyma, displayed an extremely dense and compact arborization. These cells were $\mathrm{CC}^{-}, \mathrm{GFAP}^{-}$, and S- $100 \beta^{+}$and likely protoplasmic astrocytes (Bignami and Dahl, 1974) (Fig. $2 E$ ). Some of the ependymal cells lining the third ventricle were also $\mathrm{GFP}^{+}$and were double labeled with anti-S100 $\beta$ antibody (Spassky et al., 2005) (Fig. 2 F). In addition to glial cells, plp-CRE; Z/EG mice also showed GFP expression in NeuN- or calretininpositive neurons (Fig. 2G). These results indicate that, in the bpd, plp-expressing cells give rise to all major types of CNS neural cells.

\section{plp-expressing cells are neurosphere-forming cells in vitro}

Fetal and adult neural stem cells have been defined by their ability to generate neurospheres in vitro (Doetsch et al., 1999; Uchida et al., 2000; Rietze et al., 2001). Neurospheres are floating aggregates of tripotent self-renewing cells that can differentiate into neurons, astrocytes, and oligodendrocytes (Reynolds and Weiss, 
1992). To determine whether cells that express plp were neural stem cells, we thus examined their ability to form neurospheres. The bpd of $p l p-g f p$ embryos at E9.5 and E13.5 was microdissected, dissociated, and GFP-expressing cells isolated by preparative FACS (Fig. $3 A, C$ ). The number of $\mathrm{GFP}^{+}$cells isolated per diencephalon was $1867 \pm 39(n=4)$ and $3.8 \times 10^{4} \pm$ $3.1 \times 10^{3}(n=4)$ at E9.5 and E13.5, respectively. However, the proportion of GFPexpressing cells decreased with age, from $17 \%$ at E9.5 down to $8 \%$ at E13.5 (Fig. $3 B, D)$. To characterize the identity of the labeled cells, $\mathrm{GFP}^{+}$cells were immunostained with cell-type-specific markers $2 \mathrm{~h}$ after sorting. At E9.5, all the $\mathrm{GFP}^{+}$cells are nestin $^{+}$and $\mathrm{BLBP}^{-}$, whereas at E13.5, $60 \pm 5 \%(n=5)$ of these cells were BLBP ${ }^{+}$. Of interest, $22 \pm 2 \%(n=4)$ of $\mathrm{GFP}^{+}$cells isolated at E13.5 were already postmitotic $\mathrm{NeuN}^{+}$neurons.

To test their self-renewal and differentiation potentialities, isolated $\mathrm{GFP}^{+}$cells were cultivated at clonal density to form neurospheres. Either 50 or $10 \mathrm{GFP}^{+}$cells (at E9.5 and E13.5, respectively) were sorted into wells of a 96-well plate containing serum-free medium and FGF-2 plus EGF as mitogens. After $9-10 \mathrm{~d}$, the plates were inspected for the formation of neurospheres. The ratio of wells containing neurospheres was 35 and $68 \%$ for cells isolated at E9.5 and E13.5, respectively. To determine the differentiation capacity of neurospheres grown from $p l p-\mathrm{GFP}^{+}$cells isolated at each developmental stage, we plated dissociated cells obtained from neurospheres or individual neurospheres on poly-D-lysine-coated tissue culture dishes and withdrew mitogens (FGF-2 and EGF) from the culture medium. After $5 \mathrm{~d}$, the cultures were fixed and triple labeled with a combination of antibodies specific for nestin, neuron-specific $\beta$-III-tubulin (TuJ1 $\mathrm{mAb})$, GFAP, and $\mathrm{O} 4$ to detect neural progenitor cells, neurons, astrocytes, and oligodendrocytes, respectively.

Although the vast majority of cells were still undifferentiated nestin ${ }^{+}$cells, all three differentiated cell types could be detected in E9.5-derived $p l p-\mathrm{GFP}^{+}$neurospheres: neurons $(2.4 \pm 0.4 \%)$, oligodendrocytes $(2.9 \pm 0.4 \%)$, and astrocytes $(5.6 \pm 0.8 \%)$.

Neurons, therefore, represented $20 \%$ of differentiated cells. We next investigated whether E13.5 plp-GFP ${ }^{+}$cells could also form tripotent neurospheres in vitro. Surprisingly, the differentiation of E13.5-derived plp-GFP ${ }^{+}$neurospheres was primarily limited to a glial fate [astrocytes $(31 \pm 3.2 \%)$ and oligodendrocytes $(2.4 \pm 0.4 \%)]$, whereas very few neurons were found $(0.03 \pm$ $0.02 \%)$. Neurospheres from E13.5 embryos were able to selfrenew when clonally replated in the appropriate media for at least three times but were never able to generate neurons. To verify

\section{E10.5} $C, D, 25 \mu \mathrm{m}$.

\section{Plp transgenic mice}
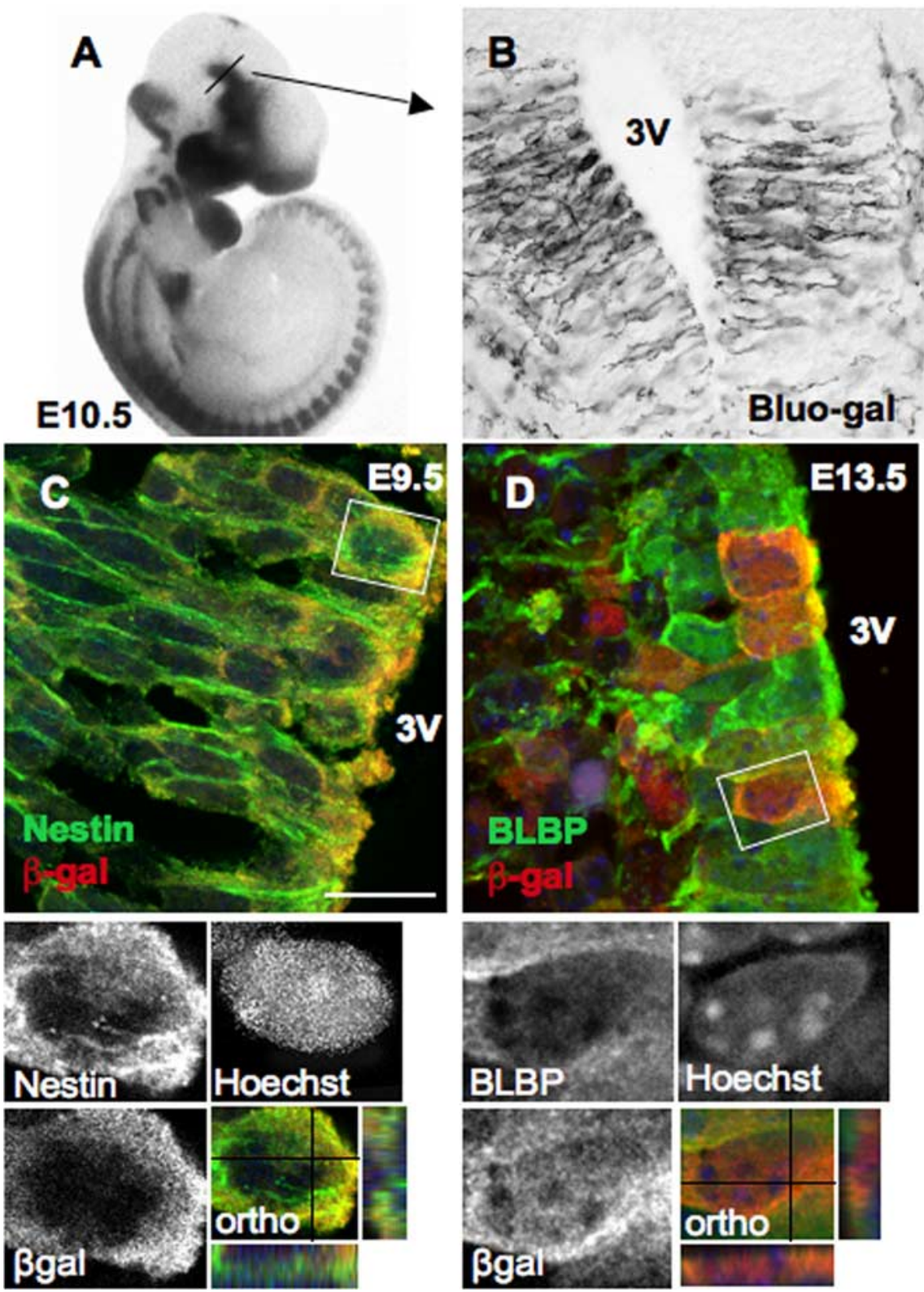

Figure 1. Sequential expression of $p / p$ by ventricular neuroepithelial and radial glial cells. $A$, Whole-mount of $p / p$-shble-lacZ embryo stained with bluo-gal at E10.5. The line indicates the plane of section in $\boldsymbol{B}$. $\boldsymbol{B}$, Coronal cryostat section of the bpd showing bluo-gal-labeled cells. C, $\boldsymbol{D}$, Confocal micrographs of single optical slices through cells in the bpd of $p / p$-shble-lacZ embryos at E9.5 and E13.5 that are double stained by immunofluorescence for $\beta$-gal and nestin $(\boldsymbol{C})$ or BLBP $(\boldsymbol{D})$ and counterstained with Hoechst reagent. Merged images, individual channels, and orthogonal analysis show that all $\beta$-gal-expressing cells in the bpd are nestin ${ }^{+}$at $\mathrm{E} 9.5$ and $\mathrm{BLBP}^{+}$at E13.5. Orthogonal images (ortho) show three-dimensional analysis of individual cells at specific sites marked by intersecting lines in the $x-, y$-, and $z$-axes. 3V, Third ventricle. Scale bar: $\boldsymbol{A}, 0.6 \mathrm{~mm} ; \boldsymbol{B}, 45 \mu \mathrm{m}$;

that the lack of neuronal differentiation among cells dissociated from E13.5 plp- $\mathrm{GFP}^{+}$neurospheres was not an artifact resulting from the dissociation process, we repeated the same differentiation experiment without dissociating the neurospheres. Immunolabeling of nondissociated neurospheres (after withdrawal of FGF-2 and EGF) showed an absence of detectable TuJ1-positive cells in E13.5 plp-GFP ${ }^{+}$neurospheres, which was in sharp contrast with the strong TuJ1 signal in E9.5 plp-GFP ${ }^{+}$neurospheres (Fig. $3 E-H$ ). These data indicate that $p l p-\mathrm{GFP}^{+}$cells have the 


\section{Plp-CRE transgenic mouse}

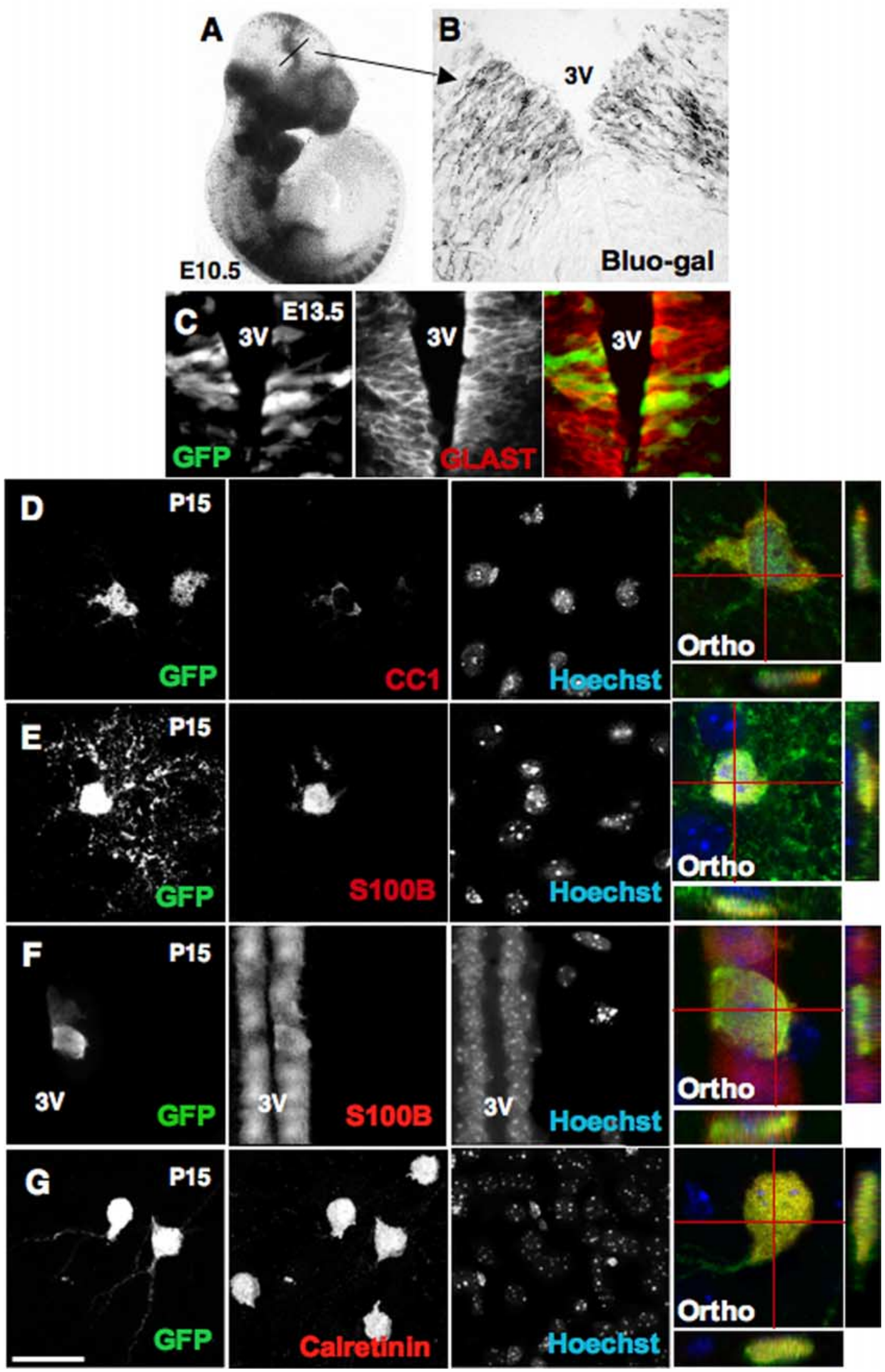

Figure 2. plp-expressing ventricular cells give rise to all neural cell populations. $A$, Whole-mount of $p / p-C R E ; R 26 R$ embryo stained with bluo-gal at E10.5. The line indicates the plane of section in $\boldsymbol{B}$. B, Coronal section across the bpd showing bluo-gal-labeled cells (compare with Fig. $1 B$ ). C, Coronal section through the bpd of a plp-CRE;Z/EG at E13.5, double immunostained with GFP and GLAST antibodies showing that all GFP ${ }^{+}$cells in the ventricular zone are GLAST ${ }^{+}$radial glial cells. $\mathbf{D}-\mathbf{G}$, At later stages, plp-activated cells give rise to all (Figure legend continues.) 
capability to self-renew but that their potentiality to differentiate into neurons disappears between E9.5 and E13.5.

\section{Ventricular diencephalic $p l p^{+}$} progenitors in vitro are fate restricted To determine the developmental potential of plp-expressing cells closer to physiological conditions, we used a clonal mouse-rat coculture system (Malatesta et al., 2000). GFP-expressing cells were FACS purified after dissection and dissociation of the bpd, as described above. After cell sorting, GFP ${ }^{+}$ cells were seeded at a clonal density on a layer of rat diencephalic cells of the same developmental stage. Individual sorted cells and their progeny were identified using mouse-specific combined neural antibodies M2 and M6 (see Materials and Methods) (Lagenaur and Schachner, 1981). We then used triple immunostaining with cell-typespecific antibodies to identify the cellular composition of the M2/M6immunoreactive clusters (Fig. 4A-H).

When isolated at E9.5, 75\% of the M2/ M6-positive cell clusters after 10 DIV consisted of a single cell type (Fig. $4 I$ ). The majority $(70 \pm 12 \% ; n=3)$ of M2/M6-positive clusters contained only neurons. Whereas just after sorting the M2/M6-positive cells were single cells, after $10 \mathrm{DIV}$, the clusters consisted mostly of 15-20 cells (mean clone size, $17 \pm 3$ cells; $n=3$ ), indicating the proliferation of sorted plp-GFP ${ }^{+}$cells. These mixed clusters were composed of $\sim 80 \%$ neurons and $20 \%$ glial cells. A more detailed examination of the glial phenotype in mixed clones generated from E9.5 plp-GFP ${ }^{+}$cells showed that these glial cells expressed RC2, BLBP, or GLAST, indicating that they were radial glial cells, i.e., progenitor cells, rather than differentiated astrocytes or oligodendrocytes. In some experiments, cultures were maintained for 5 more days [15 DIV, corresponding to postnatal days $4 / 5$ (P4/5) in vivo], and we did not observe any significant modifications in neither the proportion of mixed clones versus pure neuronal clones nor in the relative cell type composition of mixed clones. Notably, in the mixed clones, the glial components were still $\mathrm{BLBP}^{+}$, suggesting that they remained undifferentiated radial glia (Fig. $4 G, H$ ).

In contrast, when plp-GFP ${ }^{+}$cells were isolated from E13.5 brains, only few neuronal clusters were detected, and the majority (70 $\pm 4 \% ; n=4)$ of M2/M6-positive clusters analyzed after 10 DIV were pure and contained only glial cells (Fig. 4I). These results suggested that most $p l p$ progenitors have entered gliogen-

$\leftarrow$

(Figure legend continued.) four neural cell populations. Confocal micrographs of single optical slices through cells in the bpd of P15 p/p-CRE;Z/EG brains double stained by immunofluorescence for GFP and $C(1)(D), S 100 \beta(E, F)$, or calretinin $(\boldsymbol{G})$ and counterstained with Hoechst reagent. Merged images, individual channels, and orthogonal analysis show that $p / p$-activated cells give rise to $\mathrm{CC}^{+}$oligodendrocytes $(\boldsymbol{D}), \mathrm{S} 100 \beta^{+}$protoplasmic astrocytes $(\boldsymbol{E}), \mathrm{S} 100 \beta^{+}$ ependymal cells $(\boldsymbol{F})$, and calretinin ${ }^{+}$neurons $(\boldsymbol{G})$. Orthogonal images (ortho) show threedimensional analysis of individual cells at specific sites marked by intersecting lines in the $x-, y$-, and $z$-axes. 3V, Third ventricle. Scale bar: $A, 0.6 \mathrm{~mm} ; \boldsymbol{B}, 45 \mu \mathrm{m} ; \mathbf{C}-\mathbf{G}, 25 \mu \mathrm{m}$.

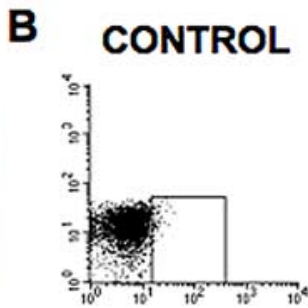

SORTING
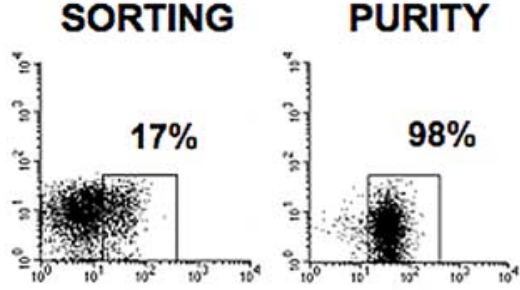

D
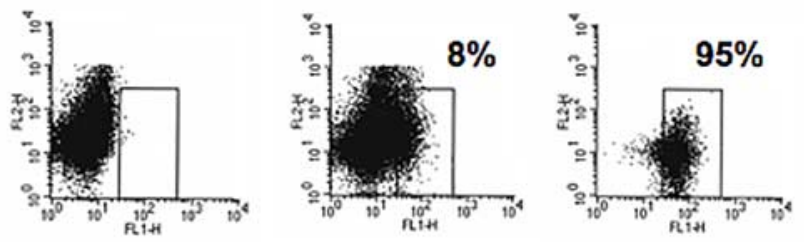

E9.5

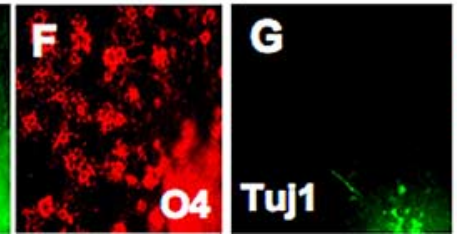

E13.5

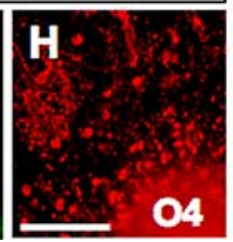

Figure 3. plp-expressing neural progenitors become glially restricted from E13.5. A, C, Sagittal view of GFP expression in the bpd of plp-GFP embryos at E9.5 (A) and E13.5 (C) B, D, FACS profiles of GFP ${ }^{+}$and GFP ${ }^{-}$cells isolated at E9.5 (B) and E13.5 (D). to select positive cells were set compared with diencephalic cells from control wild-type embryos at the same nondissociated neurospheres (under differentiation conditions) with $\operatorname{Tu} \mathbf{1}(\boldsymbol{E}, \boldsymbol{G})$ and $04(\boldsymbol{F}, \boldsymbol{H}) \mathrm{mAbs}$. Neurospheres derived from E13.5 embryos were unable to generate neurons (G). d, Dorsal, r, rostral. Scale bar: $\boldsymbol{A}, 230 \mu \mathrm{m} ; \boldsymbol{C}, 1.4 \mathrm{~mm} ; \boldsymbol{E}-\boldsymbol{H}, 140 \mu \mathrm{m}$.

esis by E13.5. At this stage, the mean size of the glial clones comprised $7 \pm 1$ cells $(n=4)$, suggesting also that these cells did not have the same proliferation characteristics as those isolated at E9.5. At both ages, diencephalic plp-GFP ${ }^{+}$cells gave rise to the same proportion of mixed M2/M6-positive clusters, i.e., clones containing both neurons and glia $(25 \pm 12, n=5$ at E9.5; $25 \pm 8$, $n=4$ at E13.5). The E13.5 mixed clusters were composed of $80 \%$ glia and $20 \%$ neurons.

It could have been possible that the restricted fate of cells isolated at E9.5 or E13.5 resulted from the environment in which the cells were cultivated. To address this question, we switched the developmental stage of the rat feeder layer. $p l p-\mathrm{GFP}^{+}$cells sorted from E9.5 and E13.5 mice were cultivated on diencephalic cells dissociated from E15.5 and E11.5 rat embryos, respectively. These heterochronic culture conditions had no influence on the fate of differentiation of $p l p-\mathrm{GFP}^{+}$cells (data not shown). Together, these results suggest that the potential of $p l p-\mathrm{GFP}^{+}$cells is mostly neurogenic at E9.5 and becomes mostly gliogenic at E13.5 and that this change is primarily cell autonomous and independent of environmental conditions.

\section{Diencephalic ventricular cells are restricted progenitors in vivo}

To assess the fate of plp progenitors in vivo, we used a transgenic mouse expressing a TM-inducible variant of the CRE recombinase (CreERT2) under the control of the plp promoter ( $p l p-$ CreERT2 mouse) (Leone et al., 2003). This transgenic mouse was crossed with the $R 26 R$ or the $Z / E G$ reporter lines. It has been 

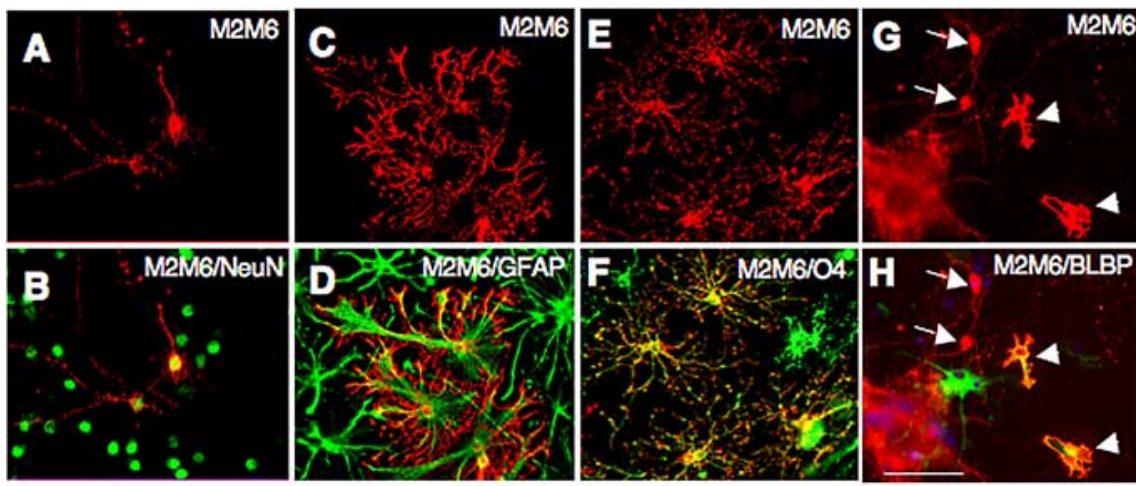

I

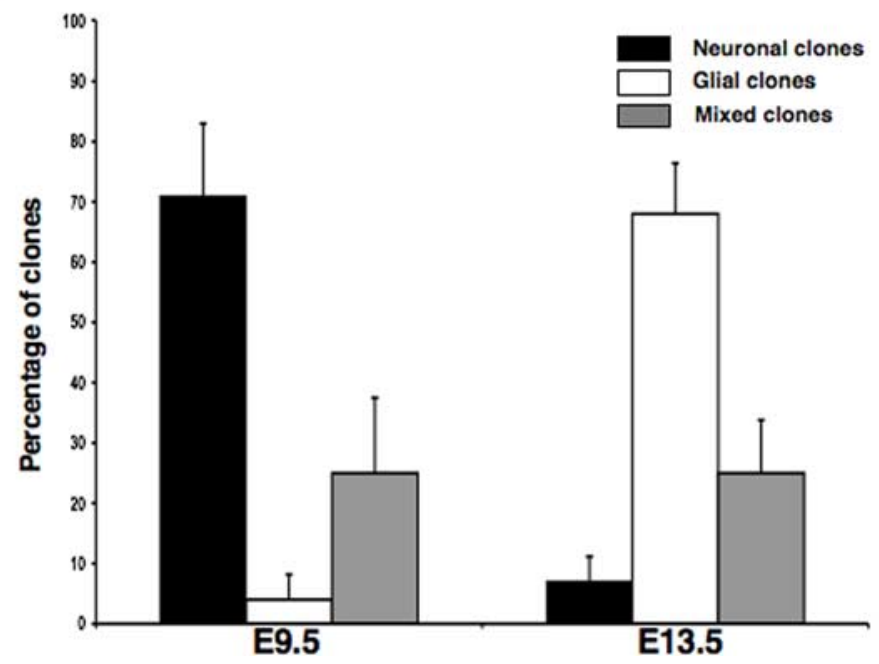

Figure 4. $\quad$ plp-expressing progenitors are mostly neuronally or glially restricted. $\boldsymbol{A}-\boldsymbol{H}$, plp-GFP ${ }^{+}$cells sorted at E9.5 and E13.5 were cultured at clonal density on an homotypic and homochronic rat feeder layer for 10 DIV and were double immunostained with the M2/M6 mAbs (red) and cell-type-specific markers (green): NeuN (neurons), GFAP (astrocytes), 04 (oligodendrocytes), and BLBP (radial glial cells). Note the M2M6/BLBP double-positive cells (arrowheads), which are contained in a mixed clone together with differentiated neurons (arrows in $\mathbf{G}, \boldsymbol{H}$ ). Scale bar, $60 \mu \mathrm{m}$. I, Quantification of the percentage of pure neuronal, pure glial, and mixed neuron-glial clones obtained after 10 DIV from fluorescence-activated cell-sorted GFP ${ }^{+}$cells at E9.5 and E13.5. Number of clones analyzed was 237 at E9.5 and 288 at E13.5.

shown previously that the CreER fusion protein translocates to the cell nucleus within $6 \mathrm{~h}$ of tamoxifen administration and that cells become marked in the following 12-24 h (Danielian et al., 1998). Therefore, by activating the CreERT2 with a single dose of tamoxifen at different embryonic stages, plp lineage cells were labeled at each stage, and their subsequent fate was determined in the young mouse brain (P0).

First, we verified that the plp-CreERT2 transgene was expressed during embryonic development exactly like the endogenous $p l p$ gene. We performed $\beta$-galactosidase histochemistry on whole-mount $p l p-C r e E R T 2 ; R 26 R$ embryos and compared the pattern of 5-bromo-4-chloro-3-indolyl- $\beta$-D-galactopyranoside (X-gal) staining with the one in age-matched plp-Cre;R26R embryos. Pregnant $p l p-C r e E R T 2 ; R 26 R$ females were injected at E9.5 with one dose of tamoxifen (typically $4 \mathrm{mg}$ ), and the embryos were collected 1 or $3 \mathrm{~d}$ later for $\beta$-galactosidase detection. Expression of the transgene was similar in plp-CreERT2;R26R and in plp-Cre;R26R embryos at E10.5 (Fig. $5 A, B$ ). We verified at E12.5 that the same cell populations were labeled on tissue sections (data not shown). On average, $144 \pm 20$ cells $(n=2)$ per diencephalon had recombined at this stage after a single tamoxifen injection. Because $\sim 1800 \mathrm{GFP}^{+}$cells were FACS purified per E9.5 plp-GFP microdissected diencephalon, the efficiency of re- combination of plp-CreERT2 can be estimated to be in the average of $8 \%$.

To determine the identity of the progeny of E9.5 or E13.5 plp-expressing progenitors, we administered tamoxifen at either age to plp-CreERT2;Z/EG or plp-CreERT2;R26R pregnant mice and analyzed the labeled cells at birth after double immunolabeling with an anti-GFP or anti- $\beta$-gal and celltype-specific antibodies. The same results were observed with either reporter mice, and the results were pooled. As predicted, the vast majority of cells labeled by tamoxifen induction at E9.5 were neurons (95 $1 \% ; n=9$ ) (Fig. 5D). These neurons had mostly migrated away from the ventricular zone to contribute to the formation of diencephalic nuclei, which were mostly composed of calretinin ${ }^{+}$neurons (Fig. $5 F$ ). Only a few $\mathrm{GFAP}^{+}$astroglial cells $(1 \pm 1 \%$; $n=9)$ were observed, most of them at a distance from the ventricular zone, near the pial surface. The remaining GFP-labeled cells $(4 \pm 1 \% ; n=9)$ were found in the ventricular layer and were identified as undifferentiated progenitors. In contrast, when tamoxifen induction was performed at E13.5, GFP-labeled cells were sparse, and the majority was double stained with antiOlig-2 Ab (77 $\pm 5 \% ; n=13)$, whereas no neurons were found (Fig. $5 E$, arrows in $G$ ). The remaining GFP-expressing cells (22 \pm $5 \% ; n=13$ ) were localized in the ventricular layer and identified as undifferentiated progenitors (Fig. 5E, arrowhead in $G$ ).

In the diencephalon, the number of glial cells generated per brain was $3 \pm 2(n=9)$ at E9.5, whereas at E13.5, the average number was $12 \pm 2(n=13)$, which was statistically different $(p<0.001$, Student's $t$ test). Assuming that the recombination efficiency was the same at each age, this difference showed that four times more glial cells were generated at E13.5 than at E9.5, which suggests that, by E13.5, a new population of $p l p$-expressing cells has emerged that is committed to a glial fate.

To test whether $p l p$ is expressed in different progenitor cells at E9.5 and E13.5, we used the plp-CRE;Z/EG mouse and took advantage of the time lag between transgene expression (CRErecombinase detection) and recombination (GFP detection). We reasoned that, at E13, all cells born between E9 and E12.5 should either express GFP only or both CRE and GFP, whereas the latest group of cells (born at approximately E13) would express only CRE and still be GFP negative. Cross-sections of E13 plp-CRE; $Z / E G$ embryos were double immunostained using anti-CRE and anti-GFP antibodies (Fig. 6A-C). Many $\mathrm{CRE}^{-} / \mathrm{GFP}^{+}$cells had migrated out of the ventricular layer toward the marginal layer (Fig. 6A-C, arrowheads). In the ventricular and subventricular layers, a few cells were double labeled with the anti-GFP and anti-CRE antibodies (Fig. 6A-C). In addition, a large number of cells localized in the ventricular layer were $\mathrm{CRE}^{+} / \mathrm{GFP}^{-}$, suggesting that they had begun to express $p l p$ shortly before the embryos were fixed (Fig. $6 A-C$, arrows). These data demonstrate the emergence at approximately E13 of a new population of cells 
expressing plp. These cells are in the same lineage but genetically clearly distinct from the $p l p$-expressing progenitors cells generated at E9.5. To determine whether plpexpressing progenitors cells segregated especially at E13.5 or continuously from E9.5 to E14.5, coronal sections of E9.5-E14.5 plpCRE;Z/EG diencephalon were double immunostained with anti-CRE and antiGFP antibodies (E9.5, $n=6$; E10.5-E13.5, $n=4 ; \mathrm{E} 14.5, n=2)$, and all $\mathrm{CRE}^{+} / \mathrm{GFP}^{-}$, $\mathrm{CRE}^{+} / \mathrm{GFP}^{+}$, and $\mathrm{CRE}^{-} / \mathrm{GFP}^{+}$cells were counted along the ventricular and subventricular zone of the diencephalon. The $\mathrm{CRE}^{+} / \mathrm{GFP}^{-}$and $\mathrm{CRE}^{+} / \mathrm{GFP}^{+}$labeled cells were found at all ages almost exclusively in the ventricular and subventricular zone, respectively (Fig. 6D). The proportion of $\mathrm{CRE}^{+} / \mathrm{GFP}^{-}$followed a clear biphasic pattern, high at E9.5-10.5, with a sharp decrease to $10 \%$ only at E11.5, an increase at E12.5, and a progressive decrease from E13.5 and E14.5. In contrast, the variation in the proportion of $\mathrm{CRE}^{-} / \mathrm{GFP}^{+}$cells provided a mirror image to that of $\mathrm{CRE}^{+} /$ $\mathrm{GFP}^{-}$. These data are compatible with the emergence of a new population of plpexpressing cells starting at E12.5.

\section{Discussion}

By specifically labeling $p l p$ progenitors and following their progeny in vivo, we demonstrate here that neurogenic $p l p^{+}$progenitor cells at E9.5 are distinct from gliogenic $p l p^{+}$ progenitor cells at E13.5. The same observation applies to $p l p^{+}$progenitors when heterotopically grown in vitro. Using the tamoxifen-inducible Cre/loxP system, we further show that, at E13.5, based on their $\mathrm{CRE}^{+} / \mathrm{GFP}^{-}$phenotype, $p l p^{+}$glioblasts are newly generated from a pool of $\left(p l p^{-}\right)$ $\mathrm{GFP}^{-}$radial glial cells. Diencephalic $p l p^{+}$ progenitors are therefore a restricted and diverse population of progenitors. These findings have led us to propose that $p l p^{+}$ neuroblasts and glioblasts are segregated early in the embryonic neuroepithelium.

This hypothesis is nevertheless confronted with alternative interpretations that support the opposing switching model. First, one can argue that $p l p^{+}$glioblasts might arise from $p l p$-negative neuroblasts, after a switch in the lineage specification of one single neural progenitor. Our in vitro data, however, indicate that this hypothesis is unlikely, because long-term cultures of E9.5 plp progenitors were never able to generate glial cells. A second contradictory interpretation would be that the same neural progenitors display various levels of plp expression during development, successively upregulating plp expression at E9.5, then downregulating before and upregulating again after E13.5. This possibility cannot be definitively discarded but is clearly not supported by the pattern

\section{PIp-creERT2; R26R PIp-cre;R26R}
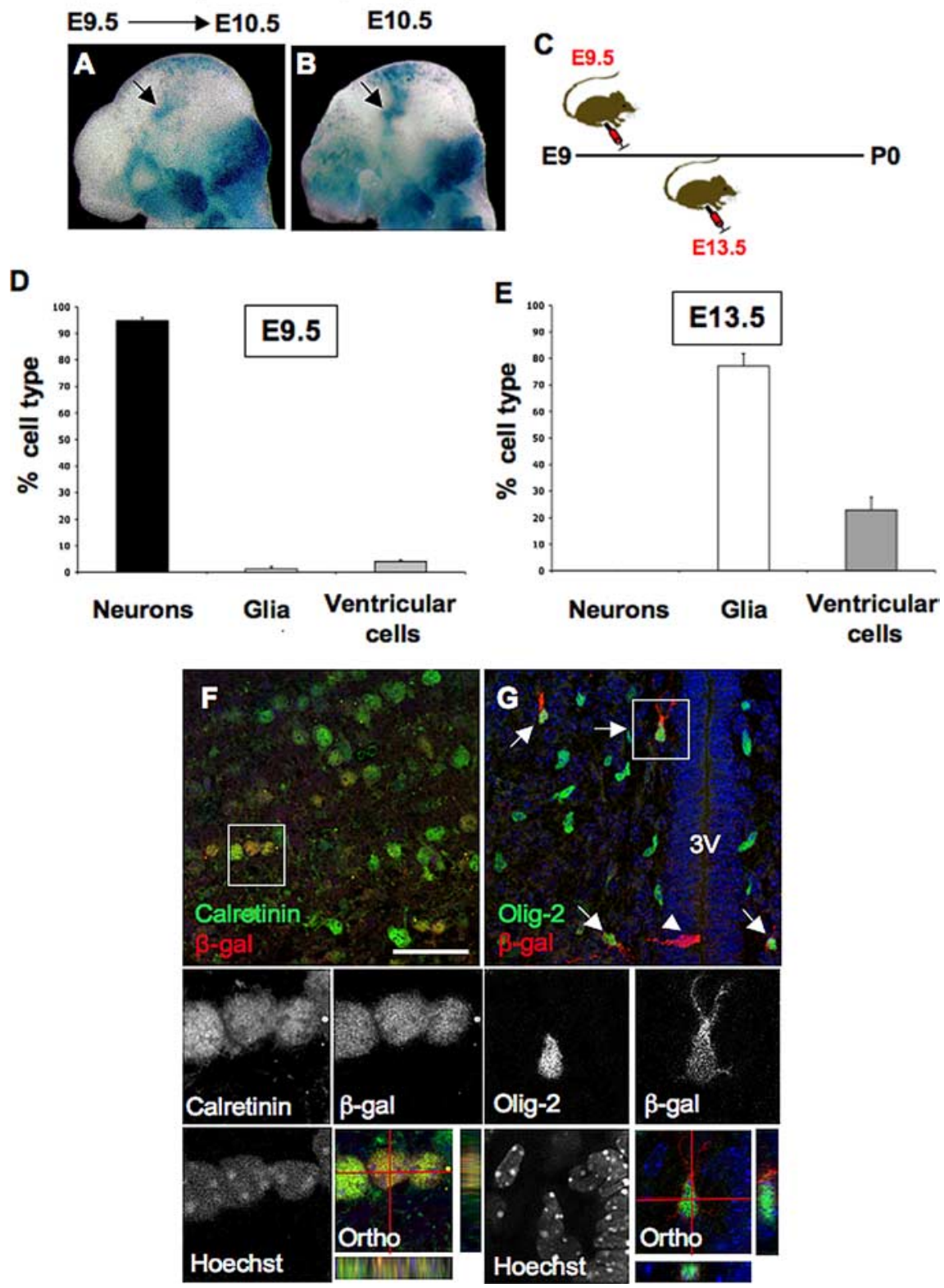

Figure 5. Tamoxifen induction reveals that $p / p$-expressing progenitors are lineage restricted in vivo. $\boldsymbol{A}, \boldsymbol{B}$, Whole-mount $\mathrm{X}$-gal staining of an E10.5 plp-CreERT2;R26R transgenic treated with tamoxifen at E9.5 (A) compared with an E10.5 plp-Cre;R26R embryo $(\boldsymbol{B})$. Arrows indicate the bpd. $\boldsymbol{C}$, Schematic representation of the tamoxifen injection protocol. Tamoxifen was injected into plp-CreERT2;Z/EG or p/p-CreERT2;R26R pregnant mice at eitherE9.5 or E13.5 and analyzed at P0. D, E, Quantification of the percentage of neurons, glia, and ventricular cells obtained at $\mathrm{PO}$ after tamoxifen injection at E9.5 and E13.5. Tamoxifen-injected animals were killed at birth (P0), and their brains were serially sectioned and double stained by immunofluorescence for GFP or $\beta$-gal and cell-type-specific markers (calretinin or NeuN for neurons and 0lig-2 or $\$ 100 \beta$ for glial cells). F, G, Confocal micrographs of single optical slices through cells in the diencephalon of $p / p$-CreERT2;R26R newborn mouse injected with tamoxifen at E9.5 $(\boldsymbol{F})$ and E13.5 $(\boldsymbol{G})$ double stained by immunofluorescence for $\beta$-gal and either calretinin $(\boldsymbol{F})$ or 0lig-2 $(\boldsymbol{G})$ and counterstained with Hoechst reagent. Merged images, individual channels, and orthogonal analysis show that $\beta$-gal-expressing cells are calretinin ${ }^{+}$and 0 lig- $2^{+}$after tamoxifen injection at E9.5 $(\boldsymbol{F})$ and E13.5 (G, arrows), respectively. Some $\beta$-gal ${ }^{+} / 0$ lig- $2^{-}$ cells with a bipolar morphology remain in the ventricular zone (arrowhead in $\boldsymbol{G}$ ). Orthogonal images (ortho) show threedimensional analysis of individual cells at specific sites marked by intersecting lines in the $x_{-}, y-$, and $z$-axes. $3 \mathrm{~V}$, Third ventricle. Scale bar: $\boldsymbol{A}, \boldsymbol{B}, 0.6 \mathrm{~mm} ; \boldsymbol{F}, \mathbf{G}, 60 \mu \mathrm{m}$. of GFP expression in ventricular progenitors between E9.5 and E13.5. If $p l p$ expression was temporally regulated in ventricular progenitors, once $p l p$ expression has been downregulated, GFP expression should still be observed, because it remains in the cytoplasm long after $p l p$ has ceased to be expressed. However, 

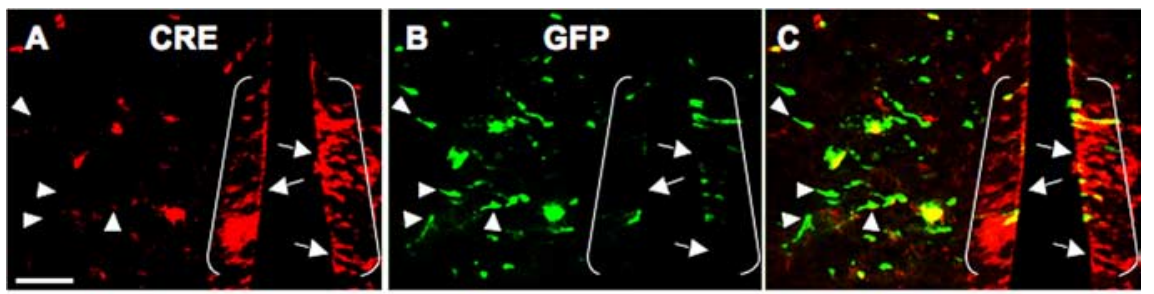

D

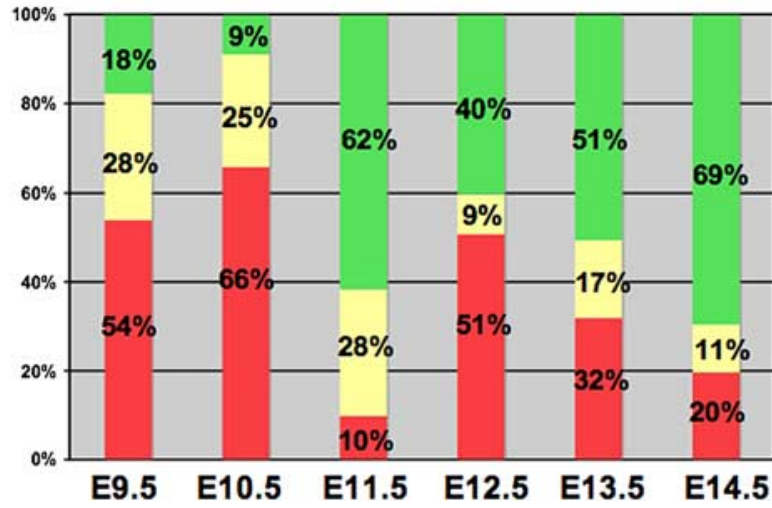

Figure 6. Emergence of CRE ${ }^{+} / \mathrm{GFP}^{-}$cells in the ventricular zone of the diencephalon at E13. Coronal cryosections of E9.5 to E14.5 (E13 shown in A-C) plp-CRE;Z/EG bpd were double stained by immunofluorescence for CRE (red) and GFP (green). At all stages analyzed, most CRE ${ }^{+} / \mathrm{GFP}^{-}$cells were localized in the ventricular zone (arrows), suggesting that they had begun to express plp shortly before the embryos were fixed. Although $\mathrm{CRE}^{+} / \mathrm{GFP}^{+}$double-positive cells were localized in both the ventricular and subventricular regions, $\mathrm{CRE}^{-} / \mathrm{GFP}^{+}$cells were only localized in the marginal regions (arrowheads). Scale bar, $400 \mu \mathrm{m} . \mathrm{D}$, Quantification of $\mathrm{CRE}^{+} / \mathrm{GFP}^{-}{ }^{-} \mathrm{CRE}^{+} / \mathrm{GFP}^{+}$, and $\mathrm{CRE}^{-} / \mathrm{GFP}^{+}$cells at each stage suggests that, although $\mathrm{CRE}^{+}$ cells are mostly absent from E11.5 ventricular zone, these cells are predominant in E9.5 and E12.5 diencephalon. Number of embryos analyzed is as follows: $n=6$ at E9.5; $n=4$ from E10.5 to E13.5; $n=3$ at E14.5.

GFP-positive neuroblasts were rare in the ventricular zone between E10.5 and E12.5, indicating that plp lineage neuroblasts most probably do not remain in the ventricular zone but are exclusively dispersed in the parenchyme. Our conclusions for $p l p$ are therefore complementary to those made for Olig-1expressing (Wu et al., 2006) and Asc1-expressing (Battiste et al., 2007) progenitor cells in the developing spinal cord. Wu et al. (2006) used a conditional cell-ablation approach to provide in vivo evidence that motoneurons and oligodendrocytes are sequentially generated in the pMN domain and do not share a common lineage-restricted progenitor. Similarly, Battiste et al. (2007) used genetic fate-mapping experiments to show that dorsal horn interneurons are derived from Ascl1-early-expressing neuronal restricted progenitors and that oligodendrocytes are derived from Ascl1-late born expressing glial restricted progenitors. In the forebrain subventricular zone, neurogenesis and gliogenesis persist into adulthood, and recent clonal culture experiments show coexistence in the germinative zone of separate pools of neural stem cells (type B cells), generating either neurons or oligodendrocytes (Menn et al., 2006), thus providing an additional argument in favor of early segregation of neuroblasts and glioblasts. Moreover, by specifically targeting neural stem cells and following their progeny in vivo, it was also shown recently that neuronal progenitors from different regions produce different types of neurons. This suggests that neural stem cells in the neonatal subventricular zone include a restricted and diverse population of progenitors (Merkle et al., 2007). Similarly, in the developing diencephalon, our results lend support to the model in which $p l p^{+}$neuroblasts and $p l p^{+}$glioblasts segregate in succession from distinct pools of neuroepithelial and radial glial cells, respectively (Fig. 7).

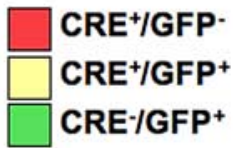

plp-early expressing progenitors can generate neurons

Although plp-early expressing neuroepithelial cells at E9.5 display stem cell properties in vitro (self-renewal and multipotency), they mostly generate neurons in vivo. In support of this generation of neurons from plp-expressing cells is the finding that Myt-1, originally identified as a $\mathrm{C} 2 \mathrm{HC}$ zinc finger protein that regulates $p l p$ expression (Kim and Hudson, 1992), is a transcription factor also essential for neuronal differentiation downstream of neurogenin-1 (Bellefroid et al., 1996). Moreover, this early fate restriction of $p l p^{+}$cells indirectly implies the existence of $p l p$-negative neuroepithelial cells that are committed at E9.5 toward the glial lineage (Fig. 7). This interpretation would be in agreement with the report by McCarthy et al. (2001) who demonstrated that, based on retroviral tracing experiments, large glial-specific clones can be targeted by E9.5 in the forebrain.

\section{plp-late-expressing progenitors generate glia}

From E11.5, the neuroepithelial cells are progressively replaced by radial glial cells. Here we show that, at E13.5 in the ventral diencephalon, $p l p$-expressing radial glial cells maintain self-renewing properties but are restricted to the generation of glial cells both in vivo and in vitro. It has been reported previously that, from E12.5, the plp transcript allows the identification of a subpopulation of oligodendrocyte precursor cells (Spassky et al., 1998, 2001a). Similar results, using Cre/loxP fate-mapping experiments, confirmed that radial glial cells mostly generate glial cells in the ventral telencephalon (Malatesta et al., 2003). Moreover, transplantation experiments in which isolated Olig- $2^{+}$cells from murine ventral spinal cord at E13.5 were directly transplanted to E2 chick spinal cord, demonstrated that these cells are intrinsically restricted to a glial fate (Mukouyama et al., 2006). Interestingly, the fate restriction of radial glial cells in the ventral diencephalon also seems to rely exclusively on cell-intrinsic cues. Indeed, the restricted gliogenic potential of $p l p{ }^{+}$radial glial cells was maintained whether the cells were cultivated on E10.5 or E14.5 rat feeder layer and was not influenced by treatment with EGF and FGF-2.

\section{Coexistence of the two differentiation models}

Altogether, our data provide compelling evidence that a subset of neurons and glial cells is sequentially generated from two different progenitors in the bpd. This does not exclude the possibility that, even in the same territory for other subsets of neural progenitors, neurons and glia share a common lineage. Because $p l p^{+}$cells represent only $8-17 \%$ of the diencephalic basal plate, it is possible that other neighboring ventricular cells are bipotent neuroglial progenitors. This has been demonstrated in Drosophila, in which in the dorsal neuroectoderm coexist progenitors with a restricted differentiation fate, either neuronal or glial, whereas others adopt a switching type of differentiation and produce neurons and glia (Schmidt et al., 1997). These authors have shown that each hemisegment of 


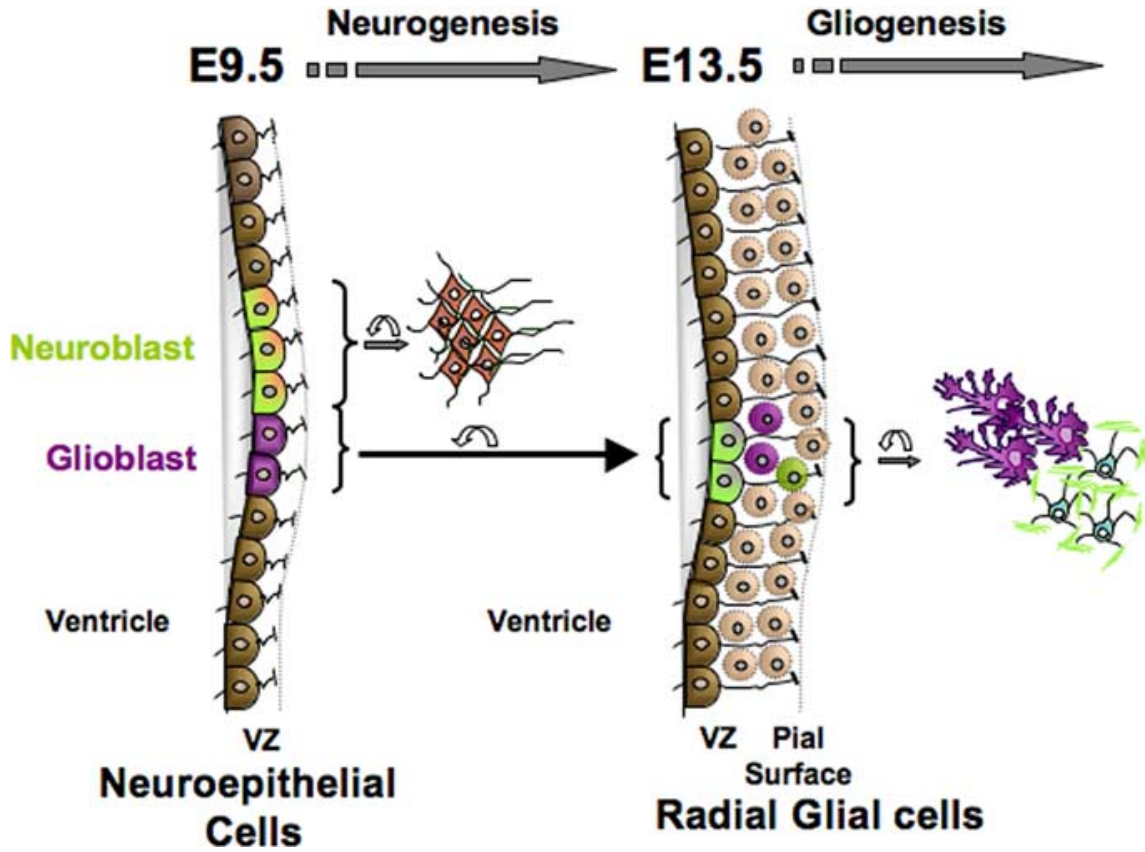

Figure 7. Proposed model for the generation of neurons and glia in the bpd. At E9.5, the ventricular zone (VZ) contains plp ${ }^{+}$ neuronal progenitors cells (green). These neuroblasts can self-renew and give rise to neurons only, which then migrate out of the ventricular zone. The $p / p^{+}$neuroblasts downregulate $p / p$ when they differentiate into neurons (red). At this developmental stage, we propose the existence of glioblasts (purple), which are not yet expressing $p / p$. AtE13.5, a new population of $p / p^{+}$cells appear from glioblasts in the ventricular zone (green and purple) and give rise mostly to glial cells. The $p / p^{+}$glioblasts will either maintain or downregulate plp expression whether they differentiate into oligodendrocytes (green cells) or astrocytes (purple cells), respectively.

the Drosophila gives rise to $\sim 350$ neurons and 30 glial cells during embryonic development. Neuroblasts from the dorsal neuroectoderm produce $\sim 90 \%$ of the glial cells in the embryonic ventral ganglion. Two of the neuroblasts give rise to glial progeny exclusively, seven neuroblasts give rise exclusively to neurons, and five give rise to glia as well as neurons. Therefore, also in mammals, neurons and glia can most probably be generated by either model. The question that remains to be elucidated concerns the mechanisms controlling one or other of these processes of differentiation and whether this entails functional consequences for two apparently similar cells having been so generated. This could have consequences in terms of repair of certain pathologies such as multiple sclerosis, in which it is important to generate new oligodendrocytes, without also generating new neurons. In contrast, in the case of stroke, it may be of interest to generate in one step both neurons and glia.

\section{References}

Anderson DJ (2001) Stem cells and pattern formation in the nervous system: the possible versus the actual. Neuron 30:19-35.

Battiste J, Helms AW, Kim EJ, Savage TK, Lagace DC, Mandyam CD, Eisch AJ, Miyoshi G, Johnson JE (2007) Ascll defines sequentially generated lineage-restricted neuronal and oligodendrocyte precursor cells in the spinal cord. Development 134:285-293.

Bellefroid EJ, Bourguignon C, Hollemann T, Ma Q, Anderson DJ, Kintner C, Pieler T (1996) X-MyT1, a Xenopus C2HC-type zinc finger protein with a regulatory function in neuronal differentiation. Cell 87:1191-1202.

Bertrand N, Castro DS, Guillemot F (2002) Proneural genes and the specification of neural cell types. Nat Rev Neurosci 3:517-530.

Bhat RV, Axt KJ, Fosnaugh JS, Smith KJ, Johnson KA, Hill DE, Kinzler KW,
Baraban JM (1996) Expression of the APC tumor suppressor protein in oligodendroglia. Glia 17:169-174.

Bignami A, Dahl D (1974) Astrocyte-specific protein and neuroglial differentiation. An immunofluorescence study with antibodies to the glial fibrillary acidic protein. J Comp Neurol 153:27-38.

Bottenstein JE, Sato GH (1979) Growth of a rat neuroblastoma cell line in serum-free supplemented medium. Proc Natl Acad Sci USA 76:514-517.

Briscoe J, Pierani A, Jessell TM, Ericson J (2000) A homeodomain protein code specifies progenitor cell identity and neuronal fate in the ventral neural tube. Cell 101:435-445.

Choi BH, Kim RC (1985) Expression of glial fibrillary acidic protein by immature oligodendroglia and its implications. J Neuroimmunol 8:215-235.

Danielian PS, Muccino D, Rowitch DH, Michael SK, McMahon AP (1998) Modification of gene activity in mouse embryos in utero by a tamoxifen-inducible form of Cre recombinase. Curr Biol 8:1323-1326.

Davis AA, Temple S (1994) A self-renewing multipotential stem cell in embryonic rat cerebral cortex. Nature 372:263-266.

Deneen B, Ho R, Lukaszewicz A, Hochstim CJ, Gronostajski RM, Anderson DJ (2006) The transcription factor NFIA controls the onset of gliogenesis in the developing spinal cord. Neuron 52:953-968.

Doe CQ, Fuerstenberg S, Peng CY (1998) Neural stem cells: from fly to vertebrates. J Neurobiol 36:111-127.

Doetsch F, Caille I, Lim DA, Garcia-Verdugo JM, Alvarez-Buylla A (1999) Subventricular zone astrocytes are neural stem cells in the adult mammalian brain. Cell 97:703-716.

Dymecki SM, Tomasiewicz H (1998) Using Flp-recombinase to characterize expansion of Wnt1-expressing neural progenitors in the mouse. Dev Biol 201:57-65.

Eisenbarth GS, Walsh FS, Nirenberg M (1979) Monoclonal antibody to a plasma membrane antigen of neurons. Proc Natl Acad Sci USA 76:4913-4917.

Fan G, Martinowich K, Chin MH, He F, Fouse SD, Hutnick L, Hattori D, Ge W, Shen Y, Wu H, ten Hoeve J, Shuai K, Sun YE (2005) DNA methylation controls the timing of astrogliogenesis through regulation of JAKSTAT signaling. Development 132:3345-3356.

Feng L, Hatten ME, Heintz N (1994) Brain lipid-binding protein (BLBP): a novel signaling system in the developing mammalian CNS. Neuron 12:895-908.

Fujita H, Fujita S (1963) [Electron microscopic studies on the histogenesis of nerve cells and neuroglia in the domestic fowl. II. On neuroglia. (in Japanese)]. Kaibogaku Zasshi 38:95-108.

Fujita H, Nakai Y (1966) [Series of atlases: morphology of the brain in electron microscopy. 4. Neuroglia] No To Shinkei 18:764-771.

Gu H, Marth JD, Orban PC, Mossmann H, Rajewsky K (1994) Deletion of a DNA polymerase beta gene segment in T cells using cell type-specific gene targeting. Science 265:103-106.

Hartfuss E, Galli R, Heins N, Gotz M (2001) Characterization of CNS precursor subtypes and radial glia. Dev Biol 229:15-30.

He W, Ingraham C, Rising L, Goderie S, Temple S (2001) Multipotent stem cells from the mouse basal forebrain contribute GABAergic neurons and oligodendrocytes to the cerebral cortex during embryogenesis. J Neurosci 21:8854-8856.

Hirano M, Goldman JE (1988) Gliogenesis in rat spinal cord: evidence for origin of astrocytes and oligodendrocytes from radial precursors. J Neurosci Res 21:155-167.

His W (1889) Die Neuroblasten und deren Entstehung im embryonalen Mark. Arch Anat Physiol/Ana Abt 249-300. 
Hogan BL, Blessing M, Winnier GE, Suzuki N, Jones CM (1994) Growth factors in development: the role of TGF-beta related polypeptide signalling molecules in embryogenesis. Dev Suppl:53-60.

Ikenaka K, Kagawa T, Mikoshiba K (1992) Selective expression of DM-20, an alternatively spliced myelin proteolipid protein gene product, in developing nervous system and in nonglial cells. J Neurochem 58:2248-2253.

Kim JG, Hudson LD (1992) Novel member of the zinc finger superfamily: A C2-HC finger that recognizes a glia-specific gene. Mol Cell Biol 12:5632-5639.

Lagenaur C, Schachner M (1981) Monoclonal antibody (M2) to glial and neuronal cell surfaces. J Supramol Struct Cell Biochem 15:335-346.

Lendahl U, Zimmerman LB, McKay RD (1990) CNS stem cells express a new class of intermediate filament protein. Cell 60:585-595.

Leone DP, Genoud S, Atanasoski S, Grausenburger R, Berger P, Metzger D, Macklin WB, Chambon P, Suter U (2003) Tamoxifen-inducible gliaspecific Cre mice for somatic mutagenesis in oligodendrocytes and Schwann cells. Mol Cell Neurosci 22:430-440.

Levitt P, Cooper ML, Rakic P (1981) Coexistence of neuronal and glial precursor cells in the cerebral ventricular zone of the fetal monkey: an ultrastructural immunoperoxidase analysis. J Neurosci 1:27-39.

Lillien L (1997) Neural development: instructions for neural diversity. Curr Biol 7:R168-R171.

Luskin MB, Parnavelas JG, Barfield JA (1993) Neurons, astrocytes, and oligodendrocytes of the rat cerebral cortex originate from separate progenitor cells: an ultrastructural analysis of clonally related cells. J Neurosci 13:1730-1750.

Lyons DA, Guy AT, Clarke JD (2003) Monitoring neural progenitor fate through multiple rounds of division in an intact vertebrate brain. Development 130:3427-3436.

Malatesta P, Hartfuss E, Gotz M (2000) Isolation of radial glial cells by fluorescent-activated cell sorting reveals a neuronal lineage. Development 127:5253-5263.

Malatesta P, Hack MA, Hartfuss E, Kettenmann H, Klinkert W, Kirchhoff F, Götz M (2003) Neuronal or glial progeny: regional differences in radial glia fate. Neuron 37:751-764.

Mayer-Proschel M, Kalyani AJ, Mujtaba T, Rao MS (1997) Isolation of lineage-restricted neuronal precursors from multipotent neuroepithelial stem cells. Neuron 19:773-785.

McCarthy M, Turnbull DH, Walsh CA, Fishell G (2001) Telencephalic neural progenitors appear to be restricted to regional and glial fates before the onset of neurogenesis. J Neurosci 21:6772-6781.

Menn B, Garcia-Verdugo JM, Yaschine C, Gonzalez-Perez O, Rowitch D, Alvarez-Buylla A (2006) Origin of oligodendrocytes in the subventricular zone of the adult brain. J Neurosci 26:7907-7918.

Merkle FT, Mirzadeh Z, Alvarez-Buylla A (2007) Mosaic organization of neural stem cells in the adult brain. Science 317:381-384.

Metzger D, Chambon P (2001) Site- and time-specific gene targeting in the mouse. Methods 24:71-80.

Mione MC, Cavanagh JF, Harris B, Parnavelas JG (1997) Cell fate specification and symmetrical/asymmetrical divisions in the developing cerebral cortex. J Neurosci 17:2018-2029.

Misson JP, Edwards MA, Yamamoto M, Caviness VS, Jr (1988) Identification of radial glial cells within the developing murine central nervous system: studies based upon a new immunohistochemical marker. Brain Res Dev Brain Res 44:95-108.

Miyata T, Kawaguchi A, Okano H, Ogawa M (2001) Asymmetric inheritance of radial glial fibers by cortical neurons. Neuron 31:727-741.

Mukouyama YS, Deneen B, Lukaszewicz A, Novitch BG, Wichterle H, Jessell TM, Anderson DJ (2006) Olig2 ${ }^{+}$neuroepithelial motoneuron progenitors are not multipotent stem cells in vivo. Proc Natl Acad Sci USA 103:1551-1556.

Noble M, Pröschel C, Mayer-Pröschel M (2004) Getting a GR(i)P on oligodendrocyte development. Dev Biol 265:33-52.

Noctor SC, Flint AC, Weissman TA, Dammerman RS, Kriegstein AR (2001) Neurons derived from radial glial cells establish radial units in neocortex. Nature 409:714-720.

Novak A, Guo C, Yang W, Nagy A, Lobe CG (2000) Z/EG, a double reporter mouse line that expresses enhanced green fluorescent protein upon Cremediated excision. Genesis 28:147-155.

Petryniak MA, Potter GB, Rowitch DH, Rubenstein JL (2007) Dlx1 and
Dlx2 control neuronal versus oligodendroglial cell fate acquisition in the developing forebrain. Neuron 55:417-433.

Puelles L, Rubenstein JL (2003) Forebrain gene expression domains and the evolving prosomeric model. Trends Neurosci 26:469-476.

Qian X, Goderie SK, Shen Q, Stern JH, Temple S (1998) Intrinsic programs of patterned cell lineages in isolated vertebrate CNS ventricular zone cells. Development 125:3143-3152.

Qian X, Shen Q, Goderie SK, He W, Capela A, Davis AA, Temple S (2000) Timing of CNS cell generation: a programmed sequence of neuron and glial cell production from isolated murine cortical stem cells. Neuron 28:69-80.

Rakic P (1971a) Guidance of neurons migrating to the fetal monkey neocortex. Brain Res 33:471-476.

Rakic P (1971b) Neuron-glia relationship during granule cell migration in developing cerebellar cortex. A Golgi and electronmicroscopic study in Macacus rhesus. J Comp Neurol 141:283-312.

Rao MS, Noble M, Mayer-Proschel M (1998) A tripotential glial precursor cell is present in the developing spinal cord. Proc Natl Acad Sci USA 95:3996-4001.

Reynolds BA, Weiss S (1992) Generation of neurons and astrocytes from isolated cells of the adult mammalian central nervous system. Science 255:1707-1710.

Rietze RL, Valcanis H, Brooker GF, Thomas T, Voss AK, Bartlett PF (2001) Purification of a pluripotent neural stem cell from the adult mouse brain. Nature 412:736-739.

Rowitch DH (2004) Glial specification in the vertebrate neural tube. Nat Rev Neurosci 5:409-419.

Sauer FC (1935) Mitosis in the neural tube. J Comp Neurol 32:377-405.

Schmechel DE, Rakic P (1979) A Golgi study of radial glial cells in developing monkey telencephalon: morphogenesis and transformation into astrocytes. Anat Embryol (Berl) 156:115-152.

Schmidt H, Rickert C, Bossing T, Vef O, Urban J, Technau GM (1997) The embryonic central nervous system lineages of Drosophila melanogaster. II. Neuroblast lineages derived from the dorsal part of the neuroectoderm. Dev Biol 189:186-204.

Shibata T, Yamada K, Watanabe M, Ikenaka K, Wada K, Tanaka K, Inoue Y (1997) Glutamate transporter GLAST is expressed in the radial gliaastrocyte lineage of developing mouse spinal cord. J Neurosci 17:9212-9219.

Sommer I, Schachner M (1981) Monoclonal antibodies (O1 to O4) to oligodendrocyte cell surfaces: an immunocytological study in the central nervous system. Dev Biol 83:311-327.

Soriano P (1999) Generalized lacZ expression with the ROSA26 Cre reporter strain. Nat Genet 21:70-71.

Spassky N, Goujet-Zalc C, Parmantier E, Olivier C, Martinez S, Ivanova A, Ikenaka K, Macklin W, Cerruti I, Zalc B, Thomas JL (1998) Multiple restricted origin of oligodendrocytes. J Neurosci 18:8331-8343.

Spassky N, Olivier C, Cobos I, LeBras B, Goujet-Zalc C, Martinez S, Zalc B, Thomas JL (2001a) The early steps of oligodendrogenesis: insights from the study of the plp lineage in the brain of chicks and rodents. Dev Neurosci 23:318-326.

Spassky N, Heydon K, Mangatal A, Jankovski A, Olivier C, Queraud-Lesaux F, Goujet-Zalc C, Thomas JL, Zalc B (2001b) Sonic hedgehogdependent emergence of oligodendrocytes in the telencephalon: evidence for a source of oligodendrocytes in the olfactory bulb that is independent of PDGFRalpha signaling. Development 128:4993-5004.

Spassky N, Merkle FT, Flames N, Tramontin AD, Garcia-Verdugo JM, Alvarez-Buylla A (2005) Adult ependymal cells are postmitotic and are derived from radial glial cells during embryogenesis. J Neurosci 25:10-18.

Stiles CD (2003) Lost in space: misregulated positional cues create tripotent neural progenitors in cell culture. Neuron 40:447-449.

Tamamaki N, Nakamura K, Okamoto K, Kaneko T (2001) Radial glia is a progenitor of neocortical neurons in the developing cerebral cortex. Neurosci Res 41:51-60.

Thomas JL, Spassky N, Perez Villegas EM, Olivier C, Cobos I, Goujet-Zalc C, Martinez S, Zalc B (2000) Spatiotemporal development of oligodendrocytes in the embryonic brain. J Neurosci Res 59:471-476.

Timsit SG, Bally-Cuif L, Colman DR, Zalc B (1992) DM-20 mRNA is expressed during the embryonic development of the nervous system of the mouse. J Neurochem 58:1172-1175.

Timsit S, Martinez S, Allinquant B, Peyron F, Puelles L, Zalc B (1995) Oligodendrocytes originate in a restricted zone of the embryonic ventral 
neural tube defined by DM-20 mRNA expression. J Neurosci 15:1012-1024.

Uchida N, Buck DW, He D, Reitsma MJ, Masek M, Phan TV, Tsukamoto AS, Gage FH, Weissman IL (2000) Direct isolation of human central nervous system stem cells. Proc Natl Acad Sci USA 97:14720-14725.

Udolph G, Prokop A, Bossing T, Technau GM (1993) A common precursor for glia and neurons in the embryonic CNS of Drosophila gives rise to segment-specific lineage variants. Development 118:765-775.

Voigt T (1989) Development of glial cells in the cerebral wall of ferrets: direct tracing of their transformation from radial glia into astrocytes. J Comp Neurol 289:74-88.

Williams BP, Read J, Price J (1991) The generation of neurons and oligodendrocytes from a common precursor cell. Neuron 7:685-693.

Wu S, Wu Y, Capecchi MR (2006) Motoneurons and oligodendrocytes are sequentially generated from neural stem cells but do not appear to share common lineage-restricted progenitors in vivo. Development 133:581-590.

Wu SX, Goebbels S, Nakamura K, Kometani K, Minato N, Kaneko T, Nave KA, Tamamaki N (2005) Pyramidal neurons of upper cortical layers generated by NEX-positive progenitor cells in the subventricular zone. Proc Natl Acad Sci USA 102:17172-17177.

Yung SY, Gokhan S, Jurcsak J, Molero AE, Abrajano JJ, Mehler MF (2002) Differentiation modulation of BMP signaling promotes the elaboration of cerebral cortical GABAergic neurons or oligodendrocytes from a common sonic hedgehog-responsive ventral forebrain progenitor species. Proc Natl Acad Sci USA 99:16273-16278.

Zinyk DL, Mercer EH, Harris E, Anderson DJ, Joyner AL (1998) Fate mapping of the mouse midbrain-hindbrain constriction using a site-specific recombination system. Curr Biol 8:665-668. 